\title{
Active earth pressure acting on retaining wall considering anisotropic seepage effect
}

\author{
Z. Hu, Z.X. Yang, S.P. Wilkinson
}

Abstract

This paper presents a general solution for active earth pressure acting on a vertical retaining wall with a drainage system along the soil-structure interface. The backfill has a horizontal surface and is composed of cohesionless and fully saturated sand with anisotropic permeability along the vertical and horizontal directions. The extremely unfavourable seepage flow on the back of the retaining wall due to heavy rainfall or other causes will dramatically increase the active earth pressure acting on the retaining walls, increasing the probability of instability. In this paper, an analytical solution to the Laplace differential governing equation is presented for seepage problems considering anisotropic permeability based on Fourier series expansion method. A good correlation is observed between this and the seepage forces along a planar surface generated via finite element analysis. The active earth pressure is calculated using Coulomb's earth pressure theory based on the calculated pore water pressures. The obtained solutions can be degenerated into Coulomb's formula when no seepage exists in the backfill. A parametric study on the influence of the degree of anisotropy in seepage flow on the distribution of active earth pressure behind the wall is conducted by varying ratios of permeability coefficients in the vertical and horizontal directions, showing that anisotropic seepage flow has a prominent impact on active earth pressure distribution. Other factors such as effective internal friction angle of soils and soil/wall friction conditions are also considered.

Keywords: active earth pressure; seepage; anisotropic permeability; retaining wall; Fourier series expansion; cohesionless soils

\section{Introduction}

Natural forces, like water, snow and wind, often change the topography in plain and mountain areas, creating unstable slopes and thus resulting in severe casualties and destructions, economic losses, and environmental damage (Budhu 2011; Ouyang et al. 2013), which demonstrates that the stability analyses of slopes and geo-structures are essential in geotechnical design. Retaining walls are structures commonly built to reinforce and provide stability for slopes, embankments, and other earthworks (Choudhury and Ahmad 2007), and have been recognized as one of the most common geo-structures which have considerable flexibility against outburst loads and are less sensitive to settlement (Ghanbari and Taheri 2012).

In practical design, the earth pressure acting on the wall due to the backfill is a major concern, and thus it is of vital importance to calculate the thrust on the wall accurately allowing the assessment of the walls safety during its operation period. Three groups of methods for computing active earth pressure are commonly used, including limit equilibrium method (Sabzevari and Ghahramani 1972; 
Motta 1994), limit analysis method (Soubra and Macuh 2002; Yang 2007), and slip line method (Chen and Li 1998; Cheng 2003; Liu and Wang 2008). The forces exerted on the wall could be obtained by either Coulomb or Rankine earth pressure theory based on limit equilibrium analysis. Historically, Coulomb pioneered the investigation of lateral earth pressure on the retaining wall by assuming a plane failure surface under limit equilibrium conditions (Coulomb 1776). Various developments rooted in Coulomb earth pressure theory have been reported considering more general ground and loading conditions, for examples in recent years, surcharge loading (Motta 1994; Greco 2005), seismic effects (Wang et al. 2008a; Ahmad 2013; Brandenberg et al. 2015), cohesive-frictional backfill (Ahmadabadi and Ghanbari 2009; Chen 2014; Xu 2015), and different slip surfaces (Li and Liu 2010; Ouyang et al. 2013; Patki et al. 2015).

Seepage flow through the backfill may affect the stability of the retaining wall. Consensus has been reached that the laminar seepage dominates in most natural flow situations (Harr, 1962). The governing equation for the seepage flow can thus be simplified as a two-dimensional Laplace equation with prescribed boundary conditions. Given the difficulties in solving this equation analytically, numerical methods are commonly employed, including the finite difference method (Soubra et al. 1999; Benmebarek et al. 2006), finite element method (Wang and Cheung 2001; Helwany 2007), and boundary element method (Barros and Santos 2012; Ai and Hu 2015). However, analytical/semi-analytical procedures are still available for the 2-D Laplace equation under certain circumstances (Banejee and Muleshkov 1992; Wang et al. 2012). For a vertical retaining wall with a drainage system along the soil-structure interface, Barros (2006) proposed an analytical method to solve the seepage problem. Wang et al. (2008b) reviewed the Coulomb-type active earth pressure acting on a retaining wall under varying drainage conditions. The effect of saturation conditions of the backfill has also been assessed for practical applications (Santos and Barros 2015). Apart from that, analytical/semi-analytical methods are also preferably applied to solve the seepage flow acting on inclined walls with sloping backfills (Soubra and Macuh 2002) and caisson quay walls (Dakoulas and Gazetas 2008). However, the effect of anisotropic seepage flow due to different permeability coefficients in vertical and horizontal directions is rarely considered in the calculation of earth pressure.

The permeability coefficient is the most significant factor affecting the seepage field (Budhu 2011). Most backfills of retaining structures are formed through a sedimentation process and display some degree of anisotropy of permeability, due to their deposition process and stress conditions (Jeng et al. 2001; Ai and Wu 2009; Rafiezadeh and Ashtiani 2014). Field measurements reveal that the permeability in the horizontal direction could be several times that of the vertical direction (Kenney 1963; Head 1988; Jeng et al. 2001; Hazelton and Murphy 2007). Zhang et al. (2015) reported that anisotropic soil permeability can significantly affect the distribution of pore water pressure and earth pressure along tunnel working surfaces and linings, indicating that the existing assumption of isotropic soil permeability is inadequate for calculating the forces and deformation of geo-structures. 
Consequently, there is a critical need to develop alternative methods for accurately computing the seepage force and active earth pressure considering anisotropic permeability coefficients for the backfill.

The present paper aims to propose an analytical procedure for anisotropic seepage problems based on the Fourier series expansion method. In this framework, the ratio of permeability coefficients for the vertical and horizontal directions is used to calculate the distribution of pore water pressure due to anisotropic seepage flow. Comparison of the analytical seepage forces along a planar surface with finite element results shows satisfactory agreement. The solution is then applied to calculating the active earth pressure on a smooth wall based on Coulomb's earth pressure theory. Parametric studies on the anisotropic coefficient of permeability demonstrate that anisotropic seepage flow has a prominent impact on the active earth pressure distribution. Parametric study of internal friction angle of soils and soil/wall friction is also presented to show its impact on the coefficients of active earth pressure.

\section{Solution to anisotropic seepage flow}

\section{Laplace differential equation}

In the present study, a steady-state hydraulic head field around the retaining wall assuming Darcy's law with anisotropic permeability is prescribed. The Seepage analysis is carried out to determine the two-dimensional distribution of the total head $h(x, z)$, which satisfies the following Laplace differential equation (Harr, 1962),

$$
k_{x} \frac{\partial^{2} h}{\partial x^{2}}+k_{z} \frac{\partial^{2} h}{\partial z^{2}}=0
$$

where $k_{x}, k_{z}$ are coefficients of permeability in the horizontal and vertical directions, respectively. For an isotropic soil with $k_{x}=k_{z}$, Eq. (1) can be reduced to

$$
\frac{\partial^{2} h}{\partial x^{2}}+\frac{\partial^{2} h}{\partial z^{2}}=0
$$

In the sedimentary deposits as well as backfills behind the retaining walls, there is a consistent tendency for the horizontal permeability coefficient to be greater than the vertical with $k_{x} / k_{z}>1$ (Taylor 1948; Rafiezadeh and Ashtiani 2014). The coordination transformation technique can be applied to Eq. (2), which is then converted into the same format as Eq. (1), by the following transformation rule,

$$
x^{\prime}=x \sqrt{k_{z} / k_{x}}
$$

This yields the following Laplace equation in $x^{\prime}-z$ plane 


$$
\frac{\partial^{2} h}{\partial x^{\prime 2}}+\frac{\partial^{2} h}{\partial z^{2}}=0
$$

It is noted that if the solution to Eq. (2) is known, the same solution can also be applied to Eq. (4) by invoking the transformation rule expressed in Eq. (3).

Total head $h(x, z)$

The case being analysed here is illustrated in Fig. 1, where a vertical retaining wall supports the saturated cohesionless backfill with seepage flow originating from a continuous source on the horizontal surface. The retaining wall is provided with a drainage system along the soil-wall interface and the layer beneath the wall. Also, the horizontal surface at $z=0$ is an impervious layer, as seen in Fig. 1. Based on Fourier series expansion method, Barros (2006) obtained a solution to the Laplace equation for an isotropic soil whose permeability coefficient is uniformly distributed in space. However, the solution could not be used for anisotropic seepage cases. By employing the coordinate transformation technique described above, the solution to Eq. (4) in the new coordinate system can then be expressed as

$$
\begin{aligned}
h\left(x^{\prime}, z\right) & =H\left[1-\sum_{m=0}^{\infty}(-1)^{m} \frac{2}{M^{2}} \mathrm{e}^{-\frac{M x^{\prime}}{H}} \sin \frac{M(H-z)}{H}\right] \\
& =H\left(1-\sum_{m=0}^{\infty} \frac{2}{M^{2}} \mathrm{e}^{-\frac{M x^{\prime}}{H}} \cos \frac{M z}{H}\right)
\end{aligned}
$$

where

$$
M=\frac{(2 m+1) \pi}{2}
$$

To obtain the total head $h(x, z)$ in the original coordinate system, the ratio of permeability coefficient $\xi$ is introduced and is defined as

$$
\xi=\sqrt{k_{z} / k_{x}}
$$

Substituting the ratio $\xi$ into Eq. (5), the total head $h(x, z)$ can be written into

$$
\begin{aligned}
h(x, z) & =H\left[1-\sum_{m=0}^{\infty}(-1)^{m} \frac{2}{M^{2}} \mathrm{e}^{-\frac{M x \xi}{H}} \sin \frac{M(H-z)}{H}\right] \\
& =H\left(1-\sum_{m=0}^{\infty} \frac{2}{M^{2}} \mathrm{e}^{-\frac{M x \xi}{H}} \cos \frac{M z}{H}\right)
\end{aligned}
$$

Then, Eq. (8) is used to calculate the pore water pressure $u(x, z)$ at any point inside the soil mass by the following equation, 


$$
u(x, z)=\gamma_{\mathrm{w}}[h(x, z)-z]
$$

where $\gamma_{\mathrm{w}}$ is the unit weight of water. According to Darcy's law, the horizontal component of the seepage velocity along the soil/structure interface can be expressed as

$$
\left.v_{x}(x, z)\right|_{x=0}=-\left.k_{x} \frac{\partial h(x, z)}{\partial x}\right|_{x=0}=k_{x} \sum_{m=0}^{\infty} \frac{2 \xi}{M} \cos \frac{M z}{H}
$$

Therefore, the total water flow $Q$ can be calculated by the following integration

$$
Q=\int_{0}^{H} k_{x} \sum_{m=0}^{\infty} \frac{2 \xi}{M} \cos \frac{M z}{H} \mathrm{~d} z=\frac{8 G}{\pi^{2}} k_{x} \xi H
$$

where $G=0.915966 \ldots$, known as Catalan's constant (Abramowitz \& Stegun, 1972; Barros, 2006). Eq. (11) implies that the total water flow $Q$ has a linear relationship with the horizontal coefficient of permeability $k_{x}$, the ratio of permeability coefficient $\xi$ and the total head $H$.

It should be pointed out that derived seepage velocity and the total flow can only be used under laminar flow condition, which is valid for most natural flow situations. When the velocity increases, the flow pattern will become turbulent beyond the range of laminar flow, and a non-linear relationship between the velocity and the hydraulic gradient should be replaced when calculating the total water flow (Harr, 1962).

\section{FEM validation}

In order to evaluate the reliability of the solution to the pore water pressure $u(x, z)$, validations were performed using a commercial FEM software ABAQUS (ABAQUS, 2010).

Consider a vertical wall with the height $H=5 \mathrm{~m}$, supported by a fully saturated cohesionless backfill in Fig. 2, in which the soil-wall interface is provided with a drainage system that collects the percolating water through the soil mass. The seepage is assumed to be anisotropic with $\xi=0.5$ and three cases with inclination angles $\vartheta=30^{\circ}, 45^{\circ}$ and $60^{\circ}$ are investigated. The pore water pressure distribution along each surface is calculated by both the proposed formulas and the FEM, as given in Fig. 3 .

It is noted that numerical implementation of Eq. (8) involves a bounding error on $h(0,0)$ when the infinite series is truncated at a fairly few terms. However, when the Fourier series are truncated at 100 terms, the bounding error will be convergent to negligibly small value. It can be seen from Fig. 3 that the analytical solutions based on proposed formulas agree well with FEM results.

\section{Active earth pressure on smooth wall}

\section{Active earth pressure considering seepage}

In this paper, the backfill behind the retaining wall is considered as homogenous and obeys the Mohr- 
Coulomb failure criterion. The evaluation of the earth thrust, which is the resultant of earth pressures along the soil-wall interface, is performed through the equilibrium analysis of a soil wedge delimited by the wall face and a trial failure surface. Based on the Coulomb's theory, the failure surface is assumed to be planar. The soil wedge is treated as a rigid body and the forces acting along its boundaries are shown in Fig. 4 .

The pore water pressure force $U$ in an isotropic soil can be directly calculated by integrating the pore water pressure $u$ along the failure surface, as given by Barros (2006) and Barros \& Santos (2012). For cases with anisotropic seepage, the ratio of permeability coefficient is involved; therefore the pore water pressure force $U$ is given by

$$
U=\int_{0}^{H} u(a z, z) \sqrt{1+a^{2}} \mathrm{dz}=\frac{1}{2} \gamma_{w} H^{2} \bar{U}(a \xi) \sqrt{1+a^{2}}
$$

where $a=\cot \theta$ defines the inclined failure surface and $\bar{U}(a \xi)$ is expressed as

$$
\bar{U}(a \xi)=1-\sum_{m=0}^{\infty} \frac{4 \mathrm{e}^{-M a \xi}}{\left[(a \xi)^{2}+1\right] M^{3}}\left\{\sin M-a \xi \cos M+a \xi \mathrm{e}^{M a \xi}\right\}
$$

The maximum value of $P_{\mathrm{a}}$ as a function of $a$ determines the critical failure surface, expressed as

$$
P_{\mathrm{a}}=\frac{1}{2} \gamma_{\mathrm{sat}} H^{2} K_{\mathrm{as}}
$$

with

$$
K_{\mathrm{as}}=\max _{a>0} \frac{a-a^{2} \mu+\omega \mu \bar{U}(a \xi)\left(1+a^{2}\right)}{a+\mu}
$$

where $K_{\text {as }}$ is the coefficient of active earth pressure with seepage, $\omega=\gamma_{\mathrm{w}} / \gamma_{\text {sat }}$ is the saturated weight ratio and $\mu=\tan \varphi^{\prime}$ is the effective internal friction coefficient of soils.

Based on Eq. (15), the interrelation between the coefficient of active earth pressure $K_{\text {as }}$, effective internal friction angle $\varphi^{\prime}$ and ratio of permeability coefficient $\xi$ is illustrated in Fig. 5. According to Barros (2006), the influence of the saturated weight ratio $\omega$ is relatively small, thus $\omega$ can be taken as 0.5 for practical purposes. It is seen from Fig. 5 that $K_{a s}$ is greater than Coulomb's coefficients $K_{a}$, indicating that the calculation of active earth pressure will be un-conservative if the seepage effect is not considered. The discrepancy is highest for the isotropic case with $\xi=1.0$, and for anisotropic seepage flow with any given $\xi<1$, the distribution curve is bounded by these two limiting cases. It is also noted that the coefficient of active earth pressure falls with the internal friction angle $\varphi$ for both with and without seepage. Comparison between $K_{\mathrm{a}}$ and $K_{\text {as }}$ with isotropic flow indicates that the 
discrepancy becomes acuter when $\varphi^{\prime}$ increases, with only $10 \%$ when $\varphi^{\prime}=10^{\circ}$ and up to $40 \%$ when $\varphi^{\prime}=45^{\circ}$.

To further consider the effect of seepage flow on the earth pressure, Fig. 6 presents the relationship between the ratio $K_{\mathrm{as}} / K_{\mathrm{a}}$ and $\tan \varphi^{\prime}$, showing almost linear trend for any given permeability coefficient ratio $\xi$. However, the gradient of the trend increases with $\xi$ value, with $\xi=1$ of isotropic seepage flow being the steepest.

A linear relationship between $K_{\mathrm{as}} / K_{\mathrm{a}}$ and $\tan \varphi$ can be expressed into,

$$
K_{\mathrm{as}} \approx K_{\mathrm{a}}\left(1+\lambda \tan \varphi^{\prime}\right)
$$

where $\lambda$ is the gradient of the fitting line. Given that $\lambda$ is dependent on $\xi$, the linear regression shown in Fig. 6 demonstrates good agreement with calculated results. The $\lambda$ values for different $\xi$ are tabulated in Table 1 and a linear regression equation is also obtained between $\lambda$ and $\xi$ (shown in Fig. 7), expressed as

$$
\lambda=0.457 \xi-0.015
$$

\section{Effects of permeability coefficient ratio}

In above study, we assume that the maximum permeability is in the horizontal direction, thus the ratio of permeability coefficient $\xi$ varies between 0 and 1 . However, if there is no horizontal seepage, i.e. $\xi \rightarrow \infty$ with vertical seepage only, the relationship between the $K_{\mathrm{as}} / K_{\mathrm{a}}$ ratio and $\xi$ will be nonlinear according to Eqs. (13) and (15). The coefficient of active earth pressure with seepage $K_{\text {as }}$ will be more than three times Coulomb's coefficient $K_{\mathrm{a}}$ when $\tan \varphi^{\prime}=1.0$, as shown in Fig. 8.

Another special case of $\xi=0$ is that only horizontal seepage exists in the soil. The total water flow $Q$ is zero according to Eqs. (10) and (11). Based on Eqs. (13) and (15), $K_{\text {as }}$ can be simplified as

$$
\begin{gathered}
\bar{U}(0)=1-\sum_{m=0}^{\infty} \frac{4 \sin M}{M^{3}}=0 \\
K_{\text {as }}(0)=\max _{a>0} \frac{a-a^{2} \mu}{a+\mu}
\end{gathered}
$$

Thus the peak value of $K_{\text {as }}(0)$ can be obtained,

$$
K_{\text {as }}(0)=a^{2}=\tan ^{2}\left(\frac{\pi}{4}-\frac{\varphi^{\prime}}{2}\right)=K_{\mathrm{a}}
$$

with 


$$
a=\tan \left(\frac{\pi}{4}-\frac{\varphi^{\prime}}{2}\right)
$$

It can be easily seen that the Eq. (20) is Coulomb's formula, indicating that the latter is a special case of the formulas proposed in this study without seepage effect. This is because no vertical seepage occurs when $\xi=0\left(k_{z}=0\right)$, and the horizontal seepage velocity along the soil/structure interface is also vanishing as calculated by Eq. (10), leading to only hydrostatic condition exists as concerned by Coulomb's theory.

\section{Active earth pressure distribution}

According to Coulomb's theory, the active earth pressure is linearly distributed against the depth below the ground surface if the backfill is a uniform soil. Now we will evaluate the distribution of active earth pressure if the seepage exists inside the backfill. To obtain the correct pressure distribution with seepage flow, the soil inside the critical wedge is supposed to be in plastic limit equilibrium and partial forces acting on local backfill behind the retaining wall are calculated, as shown in Fig. 9.

The pore water pressure along a portion $b H(b<1)$ can be expressed as

$$
\begin{aligned}
U^{*} & =\int_{H(1-b)}^{H} u[a(z-H+b H), z] \sqrt{1+a^{2}} \mathrm{dz} \\
& =\frac{1}{2} \gamma_{w} b^{2} H^{2} \bar{U}^{*}(a \xi, b) \sqrt{1+a^{2}}
\end{aligned}
$$

with

$$
\bar{U}^{*}(a \xi, b)=1-\sum_{m=0}^{\infty} \frac{4 \mathrm{e}^{-M a b \xi}}{\left[(a \xi)^{2}+1\right] M^{3} b^{2}}\left\{\sin M-a \xi \cos M-\mathrm{e}^{M a b \xi}[\sin M(1-b)-a \xi \cos M(1-b)]\right\}
$$

Using the force equilibrium condition, the partial coefficient of active earth pressure can be obtained,

$$
K_{\mathrm{as}}^{*}(b)=\max _{a>0} \frac{a-a^{2} \mu+\omega \mu \bar{U}^{*}(a \xi, b)\left(1+a^{2}\right)}{a+\mu}
$$

According to Eq. $(24), K_{\text {as }}^{*}(b)$ can be plotted against portion parameter $b$ at different ratios of permeability coefficient $\xi$. As shown in Fig. $10, K^{*}{ }_{\text {as }}(b)$ increases with $b$ for any given $\xi$, and Barros (2006) used a linear regression line to estimate the relationship between $\kappa^{*}{ }_{\text {as }}(b)$ and $b$ for $\xi=1$. For simplicity, the linear regression could be also extended to anisotropic seepage flow for $\xi<1$, as follows.

$$
K_{\mathrm{as}}^{*}(b) \approx K_{\mathrm{a}}+b\left(K_{\mathrm{as}}-K_{\mathrm{a}}\right)
$$


Thus the active earth pressure on the wall can be expressed as

$$
p_{\mathrm{as}}=\frac{\mathrm{d} P_{\mathrm{a}}^{*}}{\mathrm{~d}(b h)}=\gamma_{\mathrm{sat}} b H\left[K_{\mathrm{a}}+\frac{3 b\left(K_{\mathrm{as}}-K_{\mathrm{a}}\right)}{2}\right]
$$

For a vertical wall with height $H=10 \mathrm{~m}$, the saturated unit weight of soil $\gamma_{\text {sat }}=20 \mathrm{kN} / \mathrm{m}^{3}$ and its effective internal friction angle $\varphi^{\prime}=30^{\circ}$, the active earth pressure $p_{\text {as }}$ with different $\xi$ can be obtained using equation (26). Considering non-dimensional quantities, the active earth pressure $p_{\text {as }}$ is presented as $p_{\text {as }}{ }^{\prime}=p_{\text {as }} / \gamma_{\text {sat }} H$, and the wall height is expressed by portion parameter $b$. As shown in Fig. 11, $p^{\prime}$ as shows a parabolic distribution along the wall. The linear distribution of Coulomb's earth pressure $p_{\mathrm{a}}$ is also plotted using the same parameters, so as to directly signify the effects of the anisotropic seepage on the earth pressure. In the case of $\xi=1.0, p_{\text {as }}$ is more than $50 \%$ greater than $p_{a}$ calculated by Coulomb's formula at the base of the wall.

\section{Active earth pressure on frictional wall}

It is noted that the soil/wall interface is rough in practical engineering, and thus the interface friction angle $\delta$ could be introduced in the calculation of $K_{\text {as }}$. Based on the method proposed by Barros (2006), the coefficient of active earth pressure with anisotropic seepage $K_{\text {as }}$ is then given by

$$
K_{\mathrm{as}}=\left[\max _{a>0} \frac{a-a^{2} \mu+\omega \mu \bar{U}(a \xi)\left(1+\mathrm{a}^{2}\right)}{a\left(1-\mu \mu^{*}\right)+\mu+\mu^{*}}\right] \sqrt{1+\mu^{* 2}}
$$

where $\mu^{*}=\tan \delta$ is the coefficient of soil/wall friction.

Fig. 12 illustrates the variation of $K_{\text {as }}$ with $\varphi^{\prime}$ with varying soil/wall friction angle $\delta$, considering isotropic seepage flow only $(\xi=1.0)$. It is seen that the relationship between $K_{\text {as }}$ and $\varphi$ is related to $\delta$. The increase in $\delta$ causes $K_{\text {as }}$ to decrease when $\varphi^{\prime}$ is relatively small, though the difference is not very significant. For the case of $\delta=\varphi^{\prime}$, with the increasing internal friction angle $\varphi^{\prime}$, a diverging trend is observed between the results of $\delta=\varphi^{\prime}$ and $\delta=0$; The maximum percentage difference for which being no more than $16 \%$ for $\delta=\varphi^{\prime}$ with $\varphi^{\prime}=45^{\circ}$. The existence of soil/wall friction may not definitely decrease the active earth thrust, but it reduces the effect of the effective friction angle $\varphi^{\prime}$. Fig. 13 shows $K_{\text {as }}$ values for different ratio of permeability coefficient $\xi$ with $\delta=0.5 \varphi^{\prime}$. The relationship between $K_{\text {as }}$ and $\varphi$ for frictional wall is similar to that for smooth wall presented in Fig. 5. Because of the relatively small discrepancy of the active earth thrust between the smooth and frictional cases, the effects of $\delta$ can be neglected and Eq. (15) can be adopted for simplicity in practical applications.

\section{Conclusions}

This paper presents an analytical procedure to calculate the active earth pressure acting on a retaining wall, considering the seepage flow through a cohesionless backfill. The focus of this paper is placed on the effect of anisotropic seepage flow on the distribution of earth pressure, which is compared with solutions based on the traditional Coulomb's earth pressure theory. The following 
conclusions can be summarized.

1) Using the Fourier series expansion method and coordinate transformation technique, the seepage problem can be analytically solved under the boundary condition above and the pore water pressure distribution within the backfill can then be obtained. The analytical results appear to show excellent agreement with the numerical results by FE analyses.

2) Coulomb-type limit equilibrium analysis is employed to calculate the active earth pressure integrated with the pore water pressure due to the seepage flow in the backfill. The coefficient of active earth pressure $K_{\text {as }}$ is found to be influenced by the ratio of permeability coefficient $\xi$. The variation of $K_{\text {as }}$ with effective friction angle $\varphi^{\prime}$ is bounded by two limiting cases: i.e. without seepage and isotropic seepage flow only. The active earth pressure increases under seepage flow conditions, such that the calculation is un-conservative if the seepage effect is not considered.

3) A linear trend is presented between $K_{\mathrm{as}} / K_{\mathrm{a}}$ and $\tan \varphi$ for a range of permeability coefficient ratios $\xi$ varying from 0 to 1 . The gradient of the trend increases with $\xi$ value, with $\xi=1$ isotropic seepage flow is the steepest. However, if no horizontal seepage occurs, i.e. $\xi \rightarrow \infty$, with vertical seepage only, the relationship between $K_{\mathrm{as}} / K_{\mathrm{a}}$ ratio and $\xi$ becomes nonlinear.

4) When $\xi=0$ no seepage occurs in the backfill, the formula of $K_{\text {as }}$ degenerates to Coulomb's $K_{\mathrm{a}}$, implying that the Coulomb's theory for active earth pressure is a special case of the proposed solutions.

5) Analysis of a partial thrust wedge indicates that the effect of water seepage leads to a parabolic earth pressure distribution along the wall face. The partial coefficient of active earth pressure $K_{\text {as }}^{*}(b)$ is linearly related to the portion ratio $b$ and increases with the ratio of permeability coefficient $\xi$. In the case of $\xi=1.0, \gamma_{\text {sat }}=20 \mathrm{kN} / \mathrm{m}^{3}$ and $\varphi^{\prime}=30^{\circ}, p_{\text {as }}$ is more than $50 \%$ greater than $p_{\text {a }}$ calculated by Coulomb's formula at the base of the wall.

6) When friction exists on the soil/wall interface, the $K_{\text {as }}$ value varies little with $\delta$ and the difference can be ignored, thus the variation style of $K_{\text {as }}$ with $\varphi^{\prime}$ for wall friction is similar to that for a smooth wall. Moreover, the existence of soil/wall friction may not always decrease the active earth thrust, but it reduces the effect of effective friction angle $\varphi^{\prime}$ when $\delta$ approaches $\varphi^{\prime}$.

In addition, when there exists a surcharge load on the surface of the backfill, the water seepage solution is still applicable, but the active earth pressure will also depend on its magnitude. For more complex ground conditions, such as a non-level ground surface, multi-layered soil, and inclined layered soil. Further analytical/semi-analytical work will be conducted to obtain the distribution of pore water pressure and effects of the soil interface such that the calculation method can be modified to apply to more general conditions. Last but not least, the proposed formulations are derived based 
on the idealised boundary and drainage conditions, which might be varied from the field conditions in practical applications. Great cautions must be taken when they are applied in practical designs, by matching the conditions in the analytical studies.

\section{List of the symbols:}

\begin{tabular}{|c|c|}
\hline$H$ & height of retaining wall \\
\hline$h$ & total water head \\
\hline$\gamma$ & unit weight of soil \\
\hline$\gamma_{\mathrm{w}}$ & unit weight of water \\
\hline$\gamma_{\text {sat }}$ & unit weight of saturated soil \\
\hline$\varphi^{\prime}$ & effective friction angle \\
\hline$\delta$ & soil/wall friction angle \\
\hline$k_{\mathrm{x}}$ and $k_{\mathrm{z}}$ & $\begin{array}{l}\text { coefficients of permeability in the horizontal and vertical directions } \\
\text { respectively }\end{array}$ \\
\hline$\xi$ & ratio of permeability coefficient \\
\hline$m$ & number of term in Fourier series \\
\hline M & function of $m,(2 m+1) \pi / 2$ \\
\hline$u$ & pore water pressure \\
\hline$U\left(U^{*}\right)$ & pore water pressure force (partial) \\
\hline $\bar{U}(\bar{U} *)$ & coefficient of pore water pressure force (partial) \\
\hline$v$ & seepage velocity \\
\hline$Q$ & total water flow \\
\hline$G$ & Catalan's constant \\
\hline$N\left(N^{*}\right)$ & effective normal force acting on the failure plane (partial) \\
\hline$T\left(T^{*}\right)$ & tangential force acting on the failure plane (partial) \\
\hline$W\left(W^{*}\right)$ & saturated wedge weight (partial) \\
\hline$\theta$ & inclination angle of failure surface \\
\hline$a$ & cotangent value of inclination angle of failure surface \\
\hline$P_{\mathrm{a}}\left(P_{\mathrm{a}}^{*}\right)$ & active earth force (partial) \\
\hline$p_{a s}$ & active earth pressure \\
\hline$p_{\text {as }}{ }^{\prime}$ & non-dimensional active earth pressure \\
\hline$K_{\text {as }}\left(K_{\text {as }}^{*}\right)$ & coefficient of active earth pressure with seepage (partial) \\
\hline$K_{\mathrm{a}}$ & Coulomb's coefficient of active earth pressure \\
\hline$\omega$ & saturated weight ratio \\
\hline$\mu$ & effective internal friction coefficient of soils \\
\hline$\mu^{*}$ & coefficient of soil/wall friction \\
\hline$\lambda$ & gradient of the linear curve $\left(K_{\mathrm{as}} / K_{\mathrm{a}}\right.$ and $\left.\tan \varphi^{\prime}\right)$ \\
\hline$b$ & portion parameter \\
\hline
\end{tabular}




\section{References}

ABAQUS (2010). ABAQUS 6.10 User's Manual.

Abramowitz M, Stegun IA (1972). Handbook of mathematical functions with formulas, graphs, and mathematical tables. New York: Dover.

Ahmad SM (2013) Pseudodynamic approach for computation of seismic passive earth resistance including seepage. Ocean Engineering 63: 63-71. DOI: 10.1016/j.oceaneng.2013.01.020.

Ahmadabadi M, Ghanbari A (2009) New procedure for active earth pressure calculation in retaining walls with reinforced cohesive-frictional backfill. Geotextiles and Geomembranes 27: 456-463. DOI: 10.1016/j.geotexmem.2009.06.004.

Ai ZY, Hu YD (2015) A coupled BEM-ALEM approach for analysis of elastic thin plates on multilayered soil with anisotropic permeability. Engineering Analysis with Boundary Elements 53: 40-45.

Ai ZY, Wu C (2009) Plane strain consolidation of soil layer with anisotropic permeability. Applied Mathematics and Mechanics 30: 1349-1356.

Banerjee S, Muleshkov A (1992) Analytical solution of steady seepage into double-walled cofferdams. Journal of Engineering Mechanics 118: 525-539. DOI: 10.1061/(ASCE)0733-9399(1992)118:3(525).

Barros PLA (2006) A Coulomb-type solution for active earth thrust with seepage. Géotechnique 56: 159-164. DOI: 10.1680/geot.2006.56.3.159.

Barros PLA, Santos PJ (2012) Coefficients of active earth pressure with seepage effect. Canadian Geotechnical Journal 49: 651-658. DOI: 10.1139/T2012-020.

Benmebarek N, Benmebarek S, Kastner R, Soubra, AH (2006) Passive and active earth pressures in the presence of groundwater flow. Géotechnique 56: 521-522.

Brandenberg SJ, Mylonakis G, Stewart JP (2015) Kinematic framework for evaluating seismic earth pressures on retaining walls. Journal of Geotechnical and Geoenvironmental Engineering 141: 04015031. DOI: 10.1061/(ASCE)GT.1943-5606.0001312.

Budhu M (2011) Soil mechanics and foundations. New York: John Wiley \& Sons.

Chen L (2014) Active earth pressure of retaining wall considering wall movement. European Journal of Environmental and Civil Engineering 18: 910-926. DOI: 10.1080/19648189.2014.911121.

Chen ZY, Li SM (1998). Evaluation of active earth pressure by the generalized method of slices. Canadian Geotechnical Journal 35: 591-599.

Cheng YM (2003) Seismic lateral earth pressure coefficients for $c-\phi$ soils by slip line method. Computers and Geotechnics 30: 661-670. DOI: 10.1016/j.compgeo.2003.07.003.

Coulomb CA (1776) Essai sur une application des règles des maximis et minimis à quelques problèmes de statique relatifs à l'architecture. Mémoires de mathématique et de physique, présentés à l'academie Royale des Sciences, Vol. 7. Paris: 343-382.

Dakoulas P, Gazetas G (2008) Insight into seismic earth and water pressures against caisson quay walls. Géotechnique 58: 95-111. DOI: 10.1680/geot.2008.58.2.95.

Ghanbari A, Taheri M (2012) An analytical method for calculating active earth pressure in reinforced retaining walls subject to a line surcharge. Geotextiles and Geomembranes 34: 1-10. DOI: 10.1016/j.geotexmem.2012.02.009.

Greco VR (2005) Active earth thrust by backfills subject to a line surcharge. Canadian Geotechnical Journal 42: 1255-1263. DOI: 10.1139/T05-038.

Harr ME (1962) Groundwater and seepage. New York: Dover.

Hazelton P, Murphy B (2007) Interpreting soil test results. Collingwood: Csiro.

Head KH (1988) Manual of soil laboratory testing, vol. 2, permeability, shear strength and compressibility tests. London: Pentech Press.

Helwany S (2007) Applied soil mechanics with ABAQUS applications. New Jersey: John Wiley \& Sons.

Jeng DS, Li L, Barry DA. (2001) Wave-induced seepage flux into anisotropic seabeds. International Journal for Numerical and Analytical Methods in Geomechanics 25: 771-787. DOI: 10.1002/nag.153.

Kenny TC (1963) Permeability ratio of repeatedly layered soils. Géotechnique 13: 325-333.

Li XG, Liu WN (2010) Study on the action of the active earth pressure by variational limit equilibrium method. International Journal for Numerical and Analytical Methods in Geomechanics 34: 991-1008. DOI: 10.1002/nag.840.

Liu FQ, Wang JH (2008) A generalized slip line solution to the active earth pressure on circular retaining walls. Computers and Geotechnics 35: 155-164. DOI: 10.1016/j.compgeo.2007.06.002.

Motta E (1994) Generalized coulomb active-earth pressure for distanced surcharge. Journal of Geotechnical Engineering 120: 1072-1079. DOI: 10.1061/(ASCE)0733-9410(1994)120:6(1072).

Ouyang CJ, Xu Q, He SM, Luo Y, Wu Y (2013) A generalized limit equilibrium method for the solution of active earth pressure on a retaining wall. Journal of Mountain Science 10: 1018-1027. DOI: 10.1007/s11629-0132576-x.

Patki MA, Mandal JN, Dewaikar DM (2015) Determination of passive earth pressure coefficients using limit equilibrium approach coupled with the Kötter equation. Canadian Geotechnical Journal 52: 1241-1254. DOI: 10.1139/cgj-2014-0351. 
Rafiezadeh K, Ataie-Ashtiani B (2014) Transient free-surface seepage in three-dimensional general anisotropic media by BEM. Engineering Analysis with Boundary Elements 46: 51-66. DOI: 10.1016/j.enganabound.2014.04.025.

Sabzevari A, Ghahramani A (1972) The limit equilibrium analysis of bearing capacity and earth pressure problems in nonhomogeneous soils. Soils and Foundations 12: 33-48.

Santos PJ, Barros PLA (2015) Active earth pressure due to soil mass partially subjected to water seepage. Canadian Geotechnical Journal 52: 1886-1891. DOI: 10.1139/cgj-2014-0367.

Soubra AH, Kastner R, Benmansour A (1999) Passive earth pressures in the presence of hydraulic gradients. Géotechnique 49: 319-330.

Soubra AH, Macuh B (2002) Active and passive earth pressure coefficients by a kinematical approach. Proceedings of the Institution of Civil Engineers-Geotechnical Engineering 155: 119-131.

Taylor DW (1956) Fundamentals of soils mechanics. London: Chapman and Hall.

Wang JJ, Liu FC, Ji CL (2008b) Influence of drainage condition on Coulomb-type active earth pressure. Soil Mechanics and Foundation Engineering 45: 161-167. DOI: 10.1007/s11204-008-9022-z.

Wang JJ, Zhang HP, Chai HJ, Zhu JG (2008a) Seismic passive resistance with vertical seepage and surcharge. Soil Dynamics and Earthquake Engineering 28: 728-737. DOI: 10.1016/j.soildyn.2007.10.004.

Wang JJ, Zhang HP, Liu MW, Chen YY (2012) Seismic passive earth pressure with seepage for cohesionless Soil. Marine Georesources \& Geotechnology 30: 86-101. DOI: 10.1080/1064119X.2011.586012.

Wang YH, Cheung YK (2001) Plate on cross-anisotropic foundation analyzed by the finite element method. Computers and Geotechnics 28: 37-54. DOI: 10.1016/S0266-352X(00)00018-5.

Xu SY, Shamsabadi A, Taciroglu E (2015) Evaluation of active and passive seismic earth pressures considering internal friction and cohesion. Soil Dynamics and Earthquake Engineering 70: 30-47. DOI: 10.1016/j.soildyn.2014.11.004.

Yang XL (2007) Upper bound limit analysis of active earth pressure with different fracture surface and nonlinear yield criterion. Theoretical and Applied Fracture Mechanics 47: 46-56. DOI: 10.1016/j.tafmec.2006.10.003.

Zhang DM, Ma LX, Zhang J, Hicher PY, Juang CH (2015) Ground and tunnel responses induced by partial leakage in saturated clay with anisotropic permeability. Engineering Geology 189: 104-115. DOI: 10.1016/j.enggeo.2015.02.005. 
Table 1 Relationship between $\lambda$ and $\xi$ values

\begin{tabular}{l|c|c|c|c}
\hline Ratio of permeability coefficient $(\xi)$ & 0.2 & 0.5 & 0.8 & 1.0 \\
\hline Gradient of the ratio of $K_{\mathrm{as}} / K_{\mathrm{a}}(\lambda)$ & 0.08 & 0.21 & 0.35 & 0.44 \\
\hline
\end{tabular}

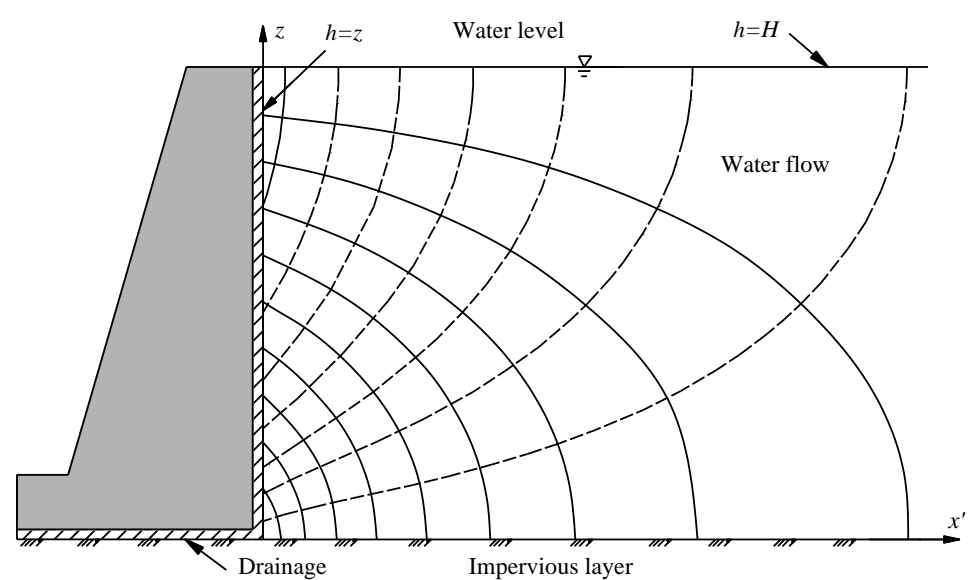

Fig. 1 Boundary conditions of seepage problem

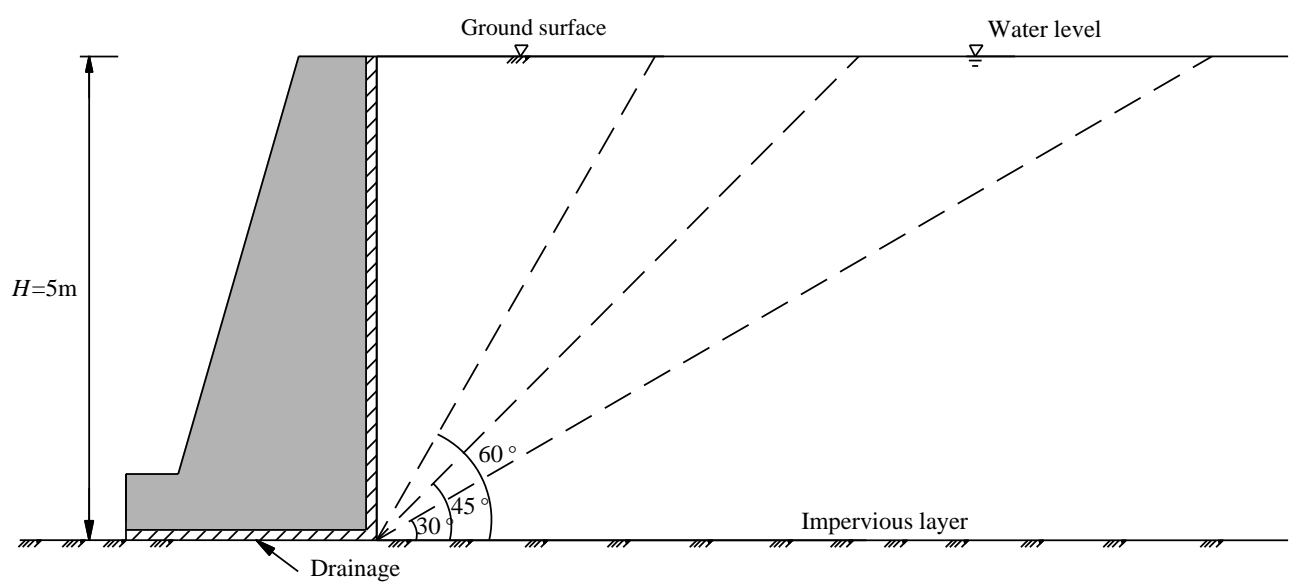

Fig. 2 Pore water pressure distribution along three specific surfaces

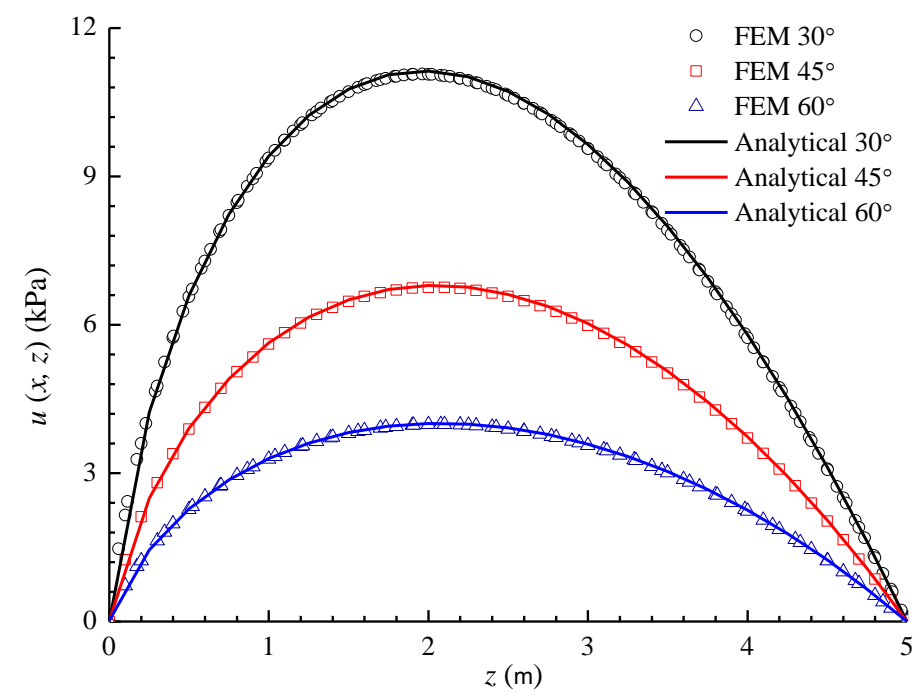

Fig. 3 Comparison of results between analytical solutions and FEM 


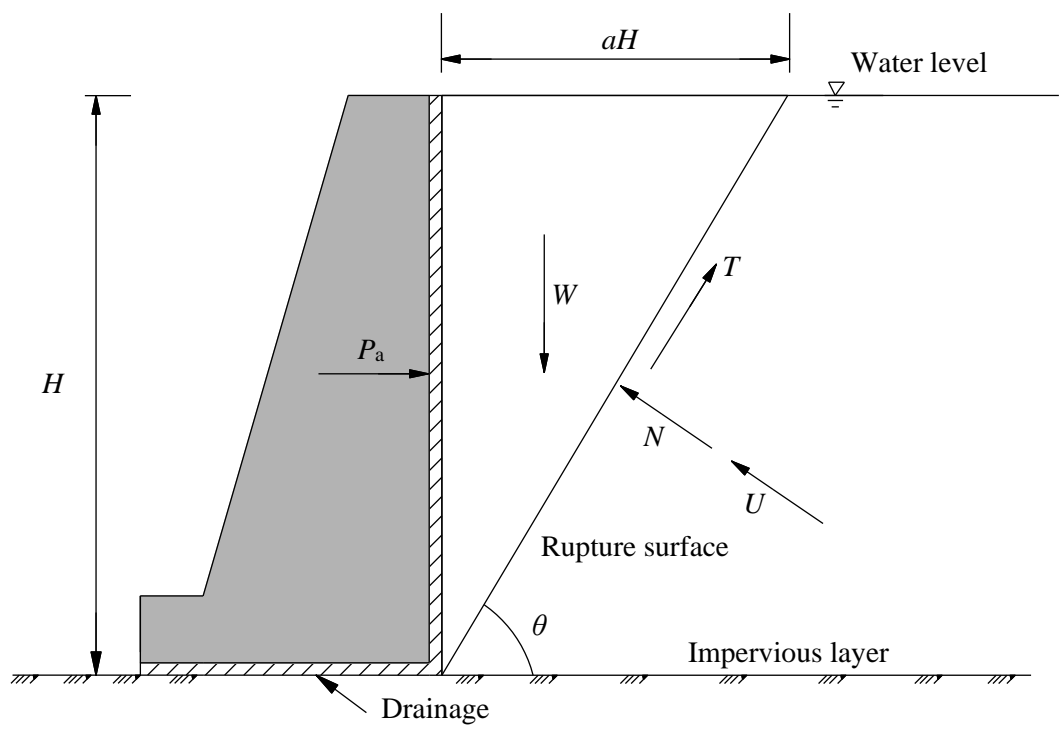

Fig. 4 Forces acting on the retaining wall and free-body diagram

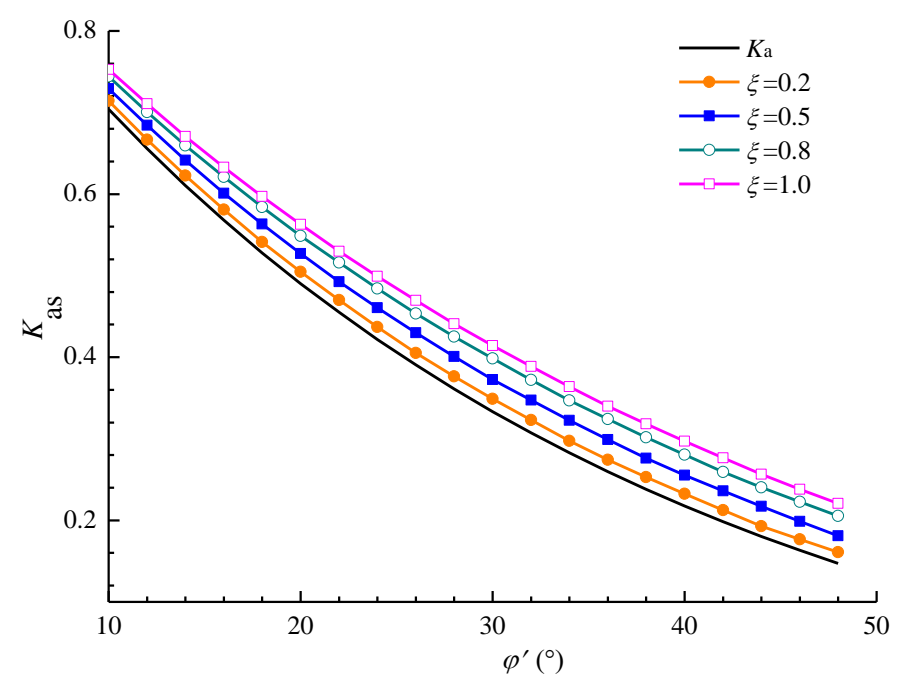

Fig. 5 Effects of $\varphi$ on coefficients of active earth pressure

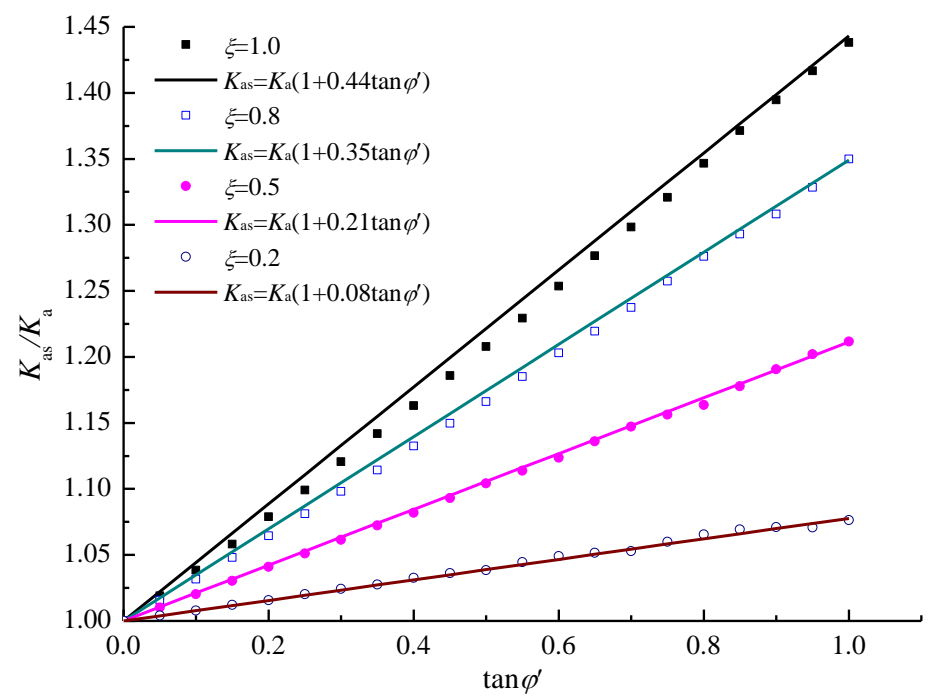

Fig. 6 Seepage flow effect with different $\tan \varphi$ ' values and fitting curves 


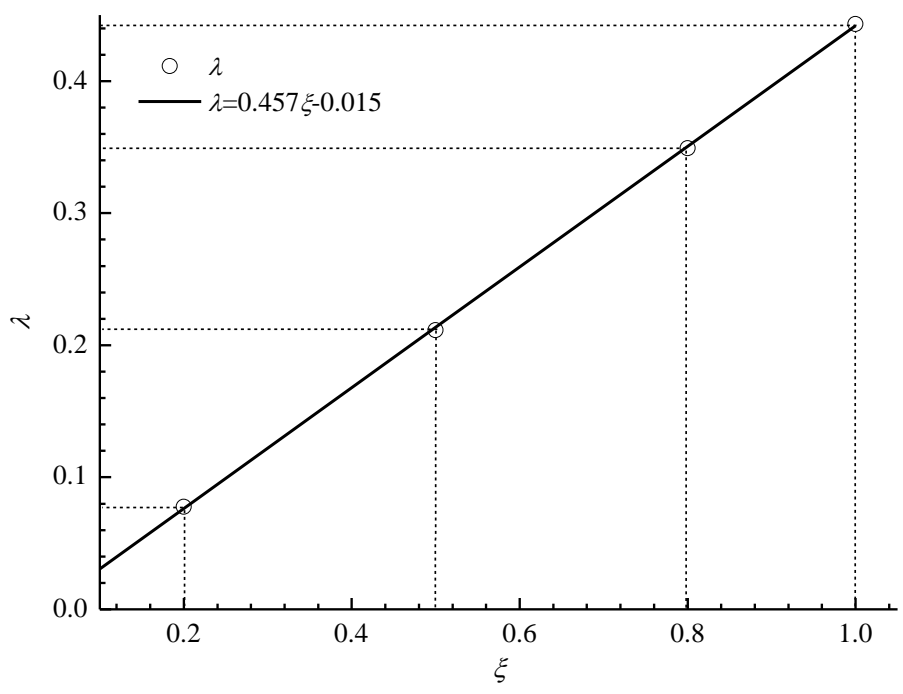

Fig. 7 Linear regression curve between $\lambda$ and $\xi$

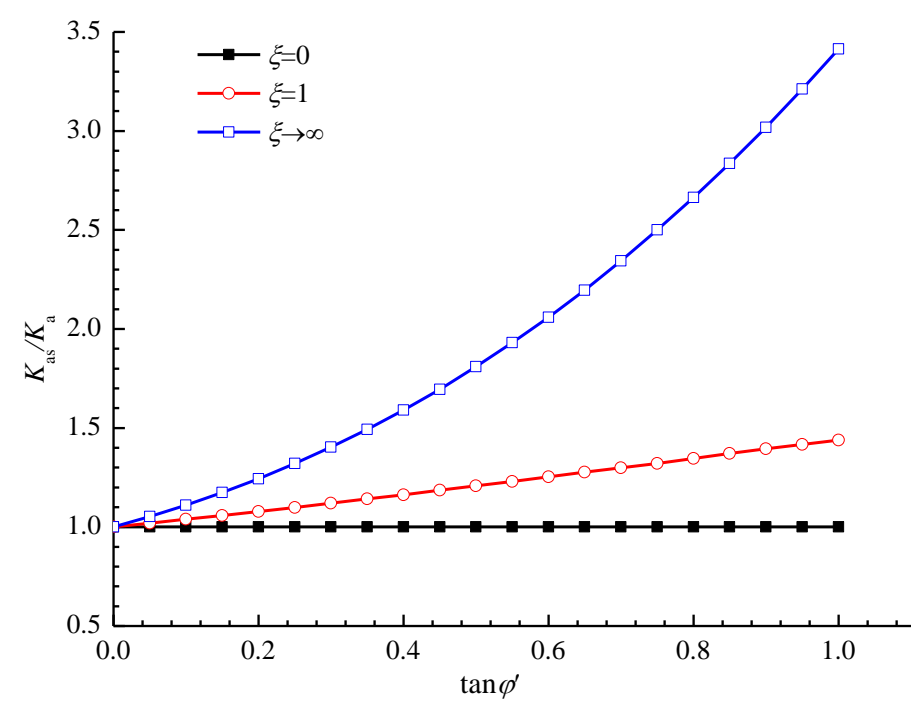

Fig. $8 K_{\text {as }} / K_{\mathrm{a}}$ for special cases of seepage flow

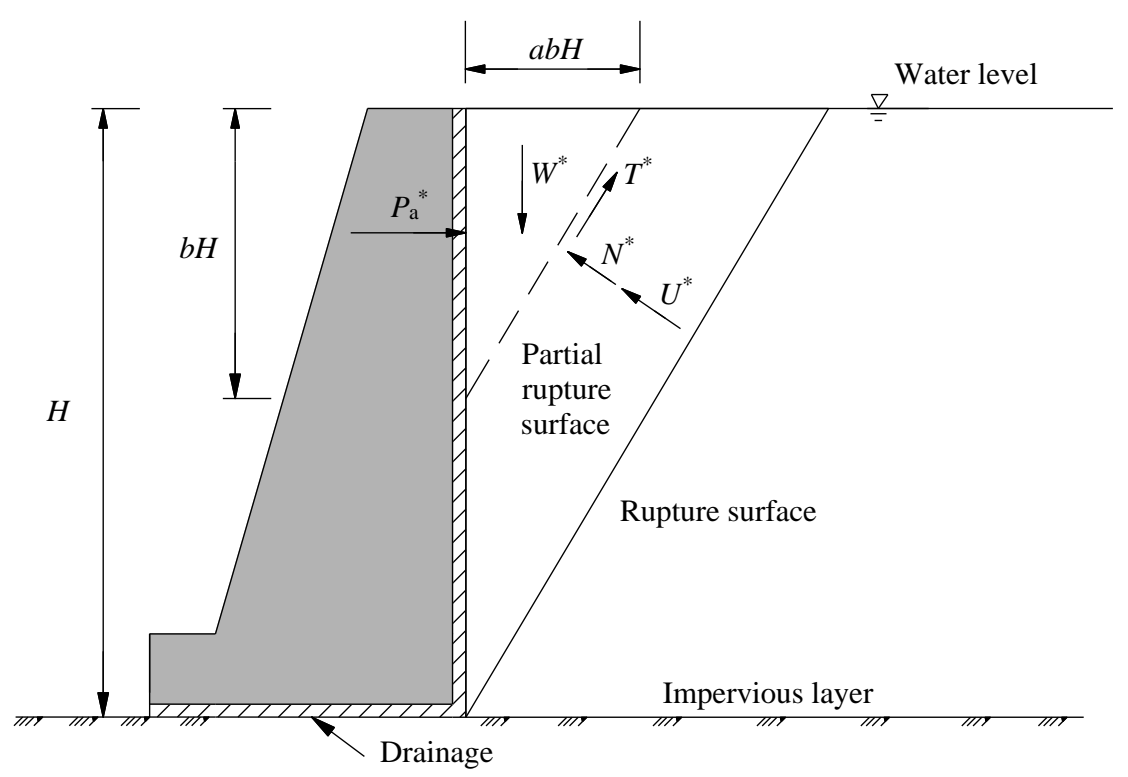

Fig. 9 Partial forces acting on the retaining wall 


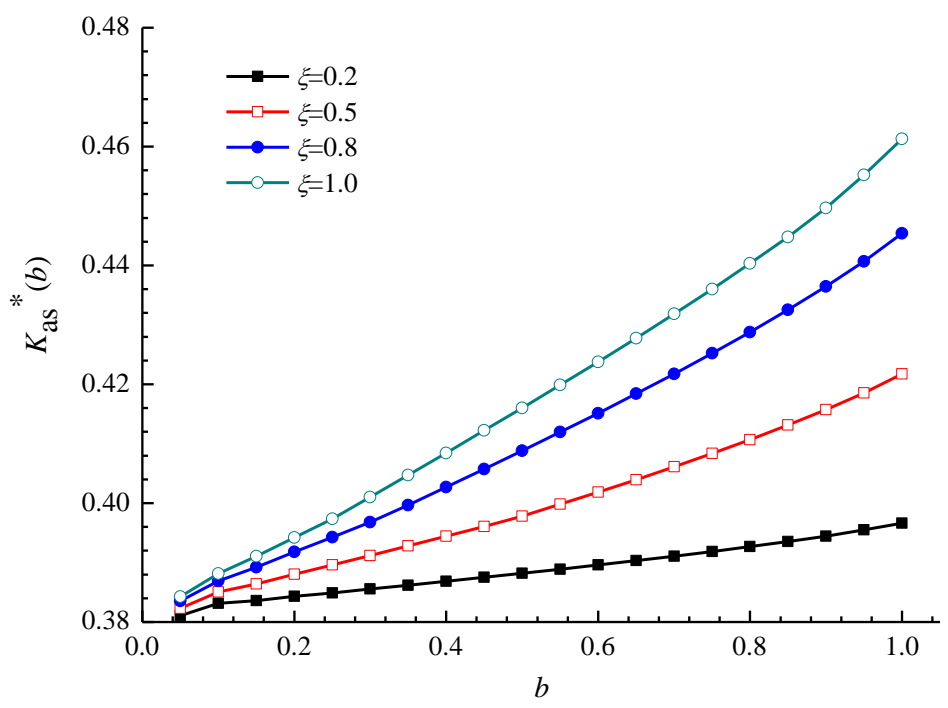

Fig. $10 K_{\text {as }}^{*}(b)$ against portion parameter $b$ for different $\xi$ values

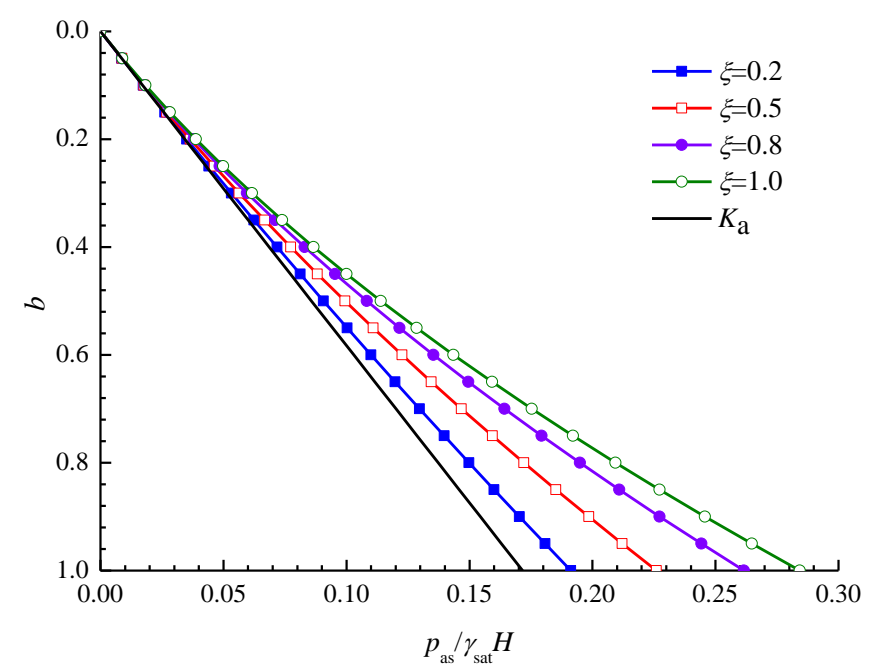

Fig. 11 Active earth pressure distribution along the wall

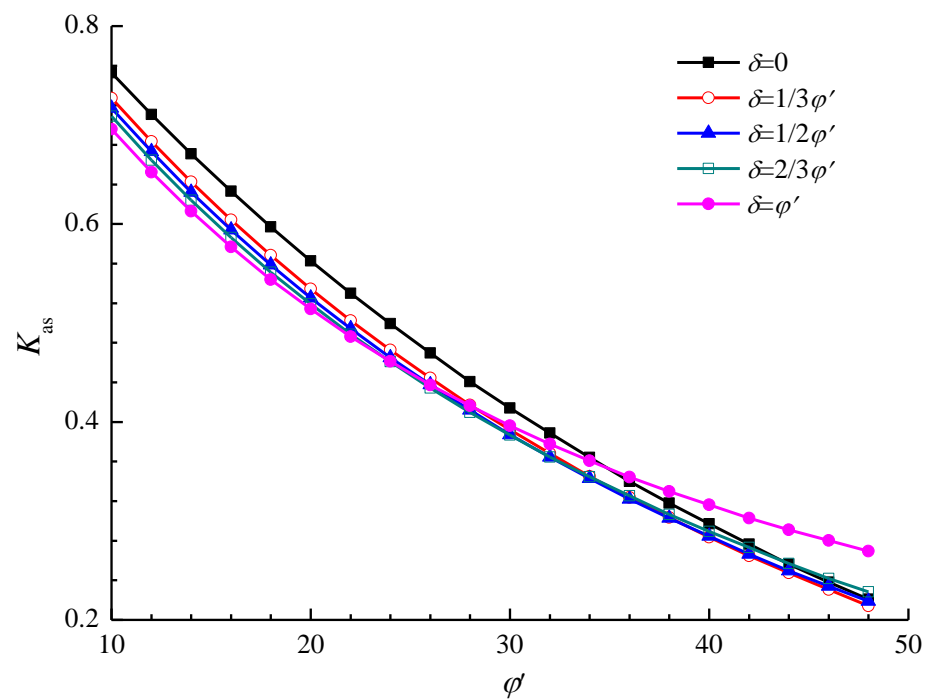

Fig. 12 Effects of $\varphi$ and $\delta$ on coefficient of active earth pressure $K_{\text {as }}$ 


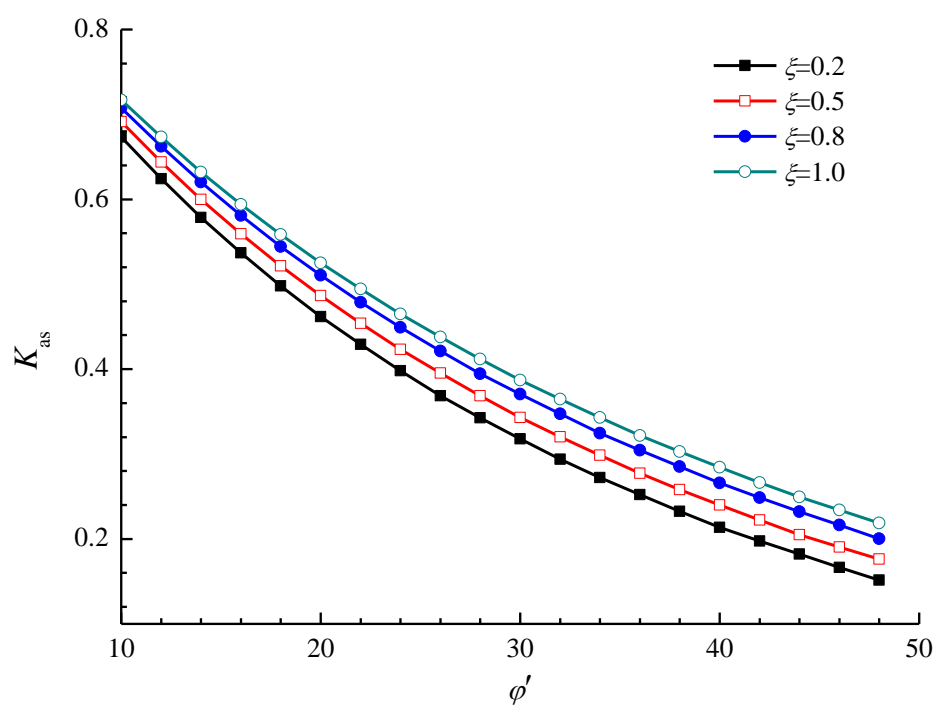

Fig. 13 Effects of $\varphi^{\prime}$ on coefficient of active earth pressure $K_{\text {as }}\left(\delta=0.5 \varphi^{\prime}\right)$ 